\title{
O USO DO GEOPROCESSAMENTO NA ANÁLISE ESPACIAL DOS CONDOMÍNIOS E LOTEAMENTOS FECHADOS EM SANTA CRUZ DO SUL- RS
}

\author{
Jonis Bozzetti ${ }^{1}$ \\ Rogério Leandro Lima da Silveira ${ }^{2}$
}

\begin{abstract}
RESUMO
A cidade de Santa Cruz do Sul, localizada na região do Vale do Rio Pardo - RS, constitui-se no principal polo agroindustrial de tabaco do mundo e também em importante centro regional de comércio e serviços. Nos últimos trinta anos, a cidade passou por intensas e desiguais transformações em seus processos de evolução urbana e de urbanização. Um desses processos tem sido a intensa produção de novos produtos imobiliários: loteamentos e condomínios fechados. Com o auxílio de técnicas de geoprocessamento, foi possível analisar melhor estes empreendimentos, identificando a segregação espacial e a injustiça fiscal que esses produtos têm representado na dinâmica de organização e de uso do espaço urbano na cidade.
\end{abstract}

Palavras-chave: Geoprocessamento. Loteamentos e Condomínios Fechados. Evolução Urbana. Segregação Espacial. Injustiça Fiscal.

\begin{abstract}
The city of Santa Cruz do Sul, located in the region of the Rio Pardo Valley in Rio Grande do Sul, constitutes the main agribusiness hub of tobacco in the world and an important regional center for commerce and services. Over the past thirty years, the city has undergone intense and unequal changes in their processes of urban evolution and urbanization. One of these processes has been the intense production of new real estate products: allotments and condominiums. With the aid of Geoprocessing techniques, we could better assess these developments, identifying spatial segregation and tax injustice that these products have represented in the dynamics of organization and use of urban space in the city.
\end{abstract}

Keywords: Geoprocessing. Allotments and Condominiums. Urban Evolution. Spatial Segregation. Tax Injustice.

\section{INTRODUÇÃO}

Esta pesquisa $^{2}$ tem como objetivo identificar e compreender as semelhanças e particularidades dos reflexos do processo de valorização imobiliária e do solo urbano, através da constituição de empreendimentos residenciais - loteamentos e condomínios fechados - na

\footnotetext{
1 Acadêmico do curso de Geografia da Universidade de Santa Cruz do Sul - UNISC. <jonisbozzzetti@hotmail.com>.

${ }^{2}$ Mestre e Doutor em Geografia Humana. Professor e Pesquisador do Departamento de História e Geografia e do Programa de Pós-Graduação em Desenvolvimento Regional da Universidade de Santa Cruz do Sul - UNISC. <rlls@unisc.br>.

${ }^{2} \mathrm{O}$ projeto de pesquisa "Valorização do Solo e Reestruturação Urbana: Estudo de Novos Produtos Imobiliários na Região dos Vales do Rio Grande do Sul", financiado pela UNISC e FAPERGS, vem sendo desenvolvido pelo Grupo de Pesquisa e Estudos Urbanos e Regionais (GEPEUR), vinculado ao Programa de Pós-Graduação em Desenvolvimento Regional da UNISC.
} 
reestruturação dos aglomerados urbanos não metropolitanos das cidades de Lajeado e Estrela (Vale do Taquari) e de Santa Cruz do Sul, Venâncio Aires e Vera Cruz (Vale do Rio Pardo).

Dentre estes municípios em estudo, diagnosticamos que Santa Cruz do Sul apresentou a produção de vinte loteamentos e condomínios fechados nos últimos quinze anos, portanto, o maior número desses empreendimentos. Desse modo, apresentamos neste artigo alguns resultados da pesquisa, referente ao uso do geoprocessamento como método para mapear e analisar a produção desses produtos imobiliários no processo de reestruturação urbana em Santa Cruz do Sul.

Inicialmente abordaremos algumas reflexões teóricas acerca dos conceitos de espaço urbano, segregação espacial, loteamentos e condomínios fechados em cidades médias, utilizando como referência as contribuições teóricas de SPOSITO (2006), CARLOS (1992) e CORRÊA (1989).

Em seguida, apresentaremos a metodologia de produção dos mapas temáticos, utilizando técnicas de geoprocessamento como principal recurso para essa atividade. Essa etapa permitiu fazer o cruzamento de dados, através de várias bases cartográficas, possibilitando, no último tópico deste artigo, analisar a espacialidade desses empreendimentos frente à renda média mensal de pessoas acima de 10 anos e as zonas fiscais (IPTU) na cidade.

\section{ESPAÇO URBANO E NOVOS PRODUTOS IMOBILIÁRIOS EM CIDADES MÉDIAS}

O estudo do espaço urbano constitui-se num importante objeto de discussão no campo das ciências humanas e sociais aplicadas, interessando diversos estudiosos como urbanistas, geógrafos, economistas, entre outros. O próprio sentido do conceito é abordado sob diferentes paradigmas, dentre os quais, concordamos com CORRÊA (1989), que define:

\footnotetext{
O espaço urbano capitalista - fragmentado, articulado, reflexo, condicionante social, cheio de símbolos e campos de lutas - é um produto social, resultado de ações acumuladas através do tempo, e engendradas por agentes que produzem e consomem espaço (CORRÊA, 1989, p.11).
}

Nesse sentido, pensar o espaço urbano em nossa sociedade capitalista convém levar em conta que as relações entre pessoas, mercadorias, decisões e investimentos se articulam ainda que diferentemente - nas diversas partes das cidades. Logo, os diferentes usos da terra, tais como centro da cidade, locais de comércio, serviços e áreas industriais, refletem a organização espacial da cidade como espaço fragmentado. 
Outras características do espaço urbano são as desigualdades socioespaciais, resultado do processo histórico de produção do sistema capitalista, desempenhando a condição de reprodução dessas relações. As diferenças de classes sociais e as desiguais formas de acesso à terra na cidade acabam por produzir áreas residenciais segregadas e levam aos conflitos sociais, colocando para os grupos de menor poder econômico a busca do direito à cidade de forma igualitária a todos.

Dessa forma, a posse de propriedade privada da terra reproduz-se como mercadoria, conforme Carlos escreve:

(...) O processo de produção da cidade tem por característica fundamental produzir um produto que é fruto do processo de valorização, que aparece sob a forma de mercadoria, que se realiza através do mercado; isto é, a terra urbana é comprada e vendida no mercado imobiliário enquanto mercadoria (CARLOS, 1992, p. 28).

Nesse processo de compra e venda da terra urbana, identifica-se os seguintes agentes que (re)produzem e consomem este espaço: os proprietários dos meios de produção, sobretudo os grandes industriais; os proprietários fundiários; os promotores imobiliários; o Estado e os grupos sociais excluídos (CORRÊA, 1989).

As ações destes agentes ocorrem por conta de seus papeis na reprodução de empreendimentos na cidade. Cada qual age sob uma determinada lógica de atuação e de acordo com interesses específicos:

* Os proprietários dos meios de produção são grandes consumidores de espaço em função de sua de necessidade de terrenos amplos e baratos;

* Os proprietários fundiários atuam na busca da maior renda fundiária;

* Os promotores imobiliários realizam, parcial ou totalmente, as seguintes operações: incorporação (operação-chave imobiliária), financiamento, estudo técnico, construção ou produção física do imóvel e comercialização;

* O Estado atua na regulamentação do uso do solo, na cobrança de impostos, no provimento de investimentos públicos, e de obras de infraestrutura, etc.

* Grupos sociais excluídos, são pessoas que habitam áreas com péssimas condições de moradia.

Ligadas ao interesse do capital, as estratégias visam, principalmente, obter a maior taxa de lucro para essa pequena fração de agentes que detêm o poder de reproduzir a cidade. Em consequência disso, produz-se na cidade a segregação espacial, marcada por diferenças socioeconômicas intraurbanas. 
No Brasil, pesquisadores, como Sposito (2006), vêm estudando a dinâmica dos agentes que produzem o espaço urbano em cidades médias. Nos últimos anos, observa-se uma significante repercussão acadêmica sobre a temática, fruto do processo recente de criação dos cursos de graduação e pós-graduação no interior do país.

O próprio conceito de cidade média vem sendo debatido na academia, constituindo uma problemática relevante no campo da Geografia Urbana. Desse modo, não há um consenso único na literatura, devido às discrepâncias entre os autores quanto ao seu significado.

A principal ideia é que o contingente populacional não é o único identificador para definir cidade média. Os dados divulgados por instituições de estudos estatísticos não são suficientes para caracterizar a realidade de cidades não metropolitanas, sendo preciso, portanto, repensar condições que melhor expressam a realidade estudada (SPOSITO, 2009 apud MAIA, 2010). Um exemplo que reforça essa concepção é citado por Souza:

[...] Uma cidade média em uma região pobre, como o Nordeste brasileiro, tenderá a não apresentar comércio e serviços tão diversificados e sofisticados quanto uma cidade de mesmo porte em uma região mais próspera, com uma presença bem mais expressiva de estratos de renda médios, como o interior de São Paulo ou o Sul do país, por exemplo (SOUZA, 2003, apud MAIA, 2010, p. 19).

É notório que, num país com dimensão territorial continental, as diferenças físicas, culturais, econômicas e sociais são relevantes. Dessa forma, concordamos também com SPOSITO (2001) quando enfatiza a importância do papel na divisão do trabalho, posição geográfica, relações espaciais da cidade e da distância de centros de maior nível hierárquico no papel regional que uma dada cidade desempenha na rede urbana em suas relações regionais, nacionais e internacionais, para reforçar o conceito de cidade média (SPOSITO, 2001 apud BRANCO, 2006).

Uma das características do processo de urbanização que vem ocorrendo com intensidade nas cidades médias brasileiras é o surgimento de uma nova forma de moradia, a qual revela dinâmicas particulares no processo de reestruturação urbana: loteamentos fechados. Cabe destacar o estudo de SPOSITO (2006) em cidades de porte médio no Estado de São Paulo. Além deste, destacam-se os trabalhos de Borsdorf (2002) sobre os Loteamentos fechados no Chile, de Icks (2002) sobre os loteamentos fechados no México, de Svampa (2001) sobre os loteamentos fechados na Venezuela e Argentina (SPOSITO, 2006).

Esses empreendimentos caracterizam-se, basicamente, por serem cercados por muros, cercas elétricas e guaritas, cujas ruas internas ficam restritas ao uso dos moradores. 
Dessa forma, o direito social à cidade é ferido, no momento que impede-se o acesso às áreas públicas.

Uma das especificidades para a construção de loteamentos fechados em cidades médias é o preço mais baixo de terras ainda não loteadas. Além disso, o rápido deslocamento ao centro é outro fator levado em conta na produção desses novos produtos imobiliários (SPOSITO, 2006).

Logo, o processo de reestruturação urbana que Santa Cruz do Sul experimentou nos últimos 30 anos produziu novas formas de moradia, notadamente condomínios e loteamentos fechados. Com veremos melhor no último tópico deste artigo, a promoção desses empreendimentos por agentes produtores do espaço urbano reforça, sobretudo, a segregação socioespacial na cidade.

\section{O GEOPROCESSAMENTO COMO FERRAMENTA PARA A ANÁLISE ESPACIAL}

O uso do geoprocessamento na atualidade vem sendo utilizado em diversas áreas do conhecimento, tais como planejamento urbano, recursos naturais, comunicação, transportes, entre outras. Essa diversa aplicabilidade se deve à necessidade de coletar informações sobre a distribuição geográfica nos mais variados estudos. Logo, Câmara e Davis definem: “o termo Geoprocessamento denota a disciplina do conhecimento que utiliza técnicas matemáticas e computacionais para o tratamento da informação geográfica" (CÂMARA; DAVIS, 2001, p. $1)$.

Em nosso estudo sobre Santa Cruz do Sul, constatamos que existiam até o ano de 2012 vinte loteamentos e condomínios fechados. Para o aprofundamento das análises empíricas desses empreendimentos, utilizamos técnicas de geoprocessamento, com o objetivo de poder verificar a espacialização desses produtos imobiliários em determinados ambientes urbanos.

Inicialmente foram adquiridos, com auxílio do projeto de pesquisa, os softwares Google Earth Pro e o Auto Cad Map 2013 para a manipulação dos dados. O primeiro, auxiliou na disponibilização das imagens de satélites e o segundo para o processamento das bases cartográficas, vetorização das redes viárias, cruzamento de dados e elaboração dos mapas. Na sequência, elaboramos a proposta metodológica, cuja estrutura é representada no fluxograma abaixo: 
Figura 1 - Fluxograma da proposta metodológica para a produção de mapas temáticos

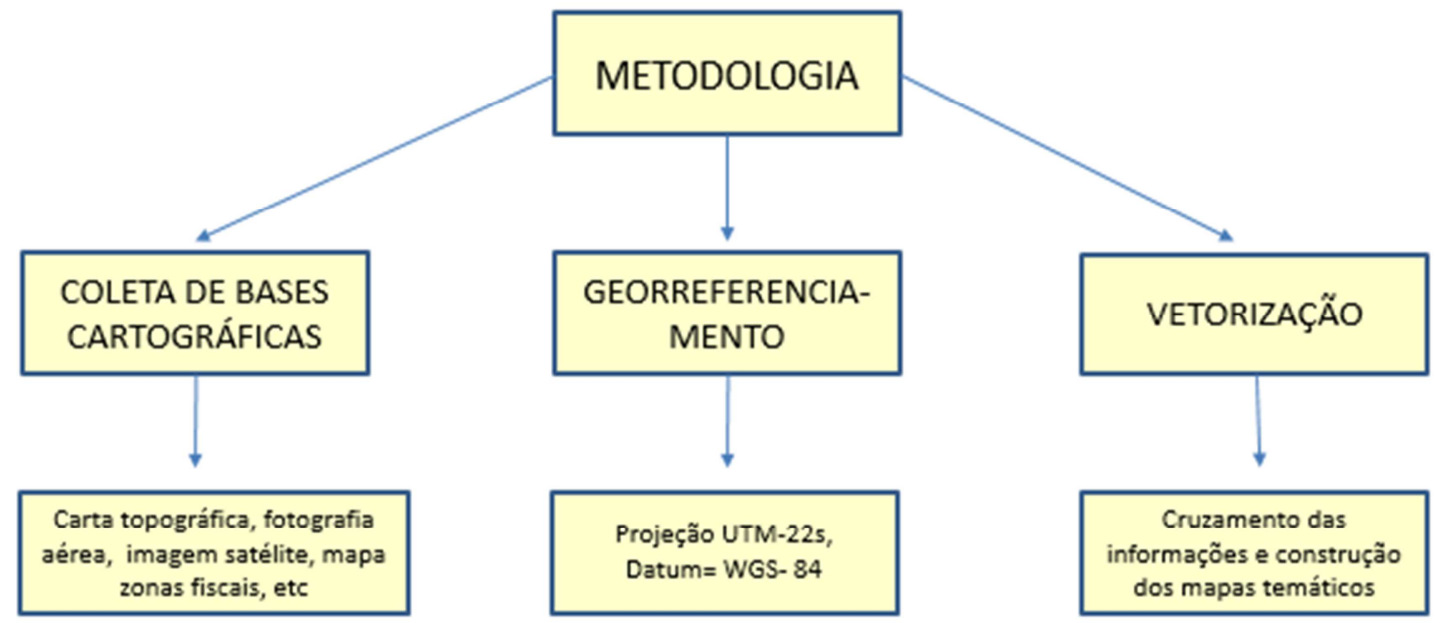

Fonte: Elaboração do autor, 2014.

No intuito de verificar a expansão urbana, zoneamento fiscal e renda média por bairro, foram coletadas as seguintes bases cartográficas: cartas topográficas do exército (1975), fotografia aérea (1996), imagem de satélite (2012) do Google Earth, mapa da Prefeitura (planta de valores do Imposto Predial e Territorial Urbano - IPTU) de 2012, e arquivos shapes e dados de Renda Média por bairro do IBGE de 2010.

Após esse levantamento, tanto os arquivos raster (imagens) como vetor (arquivos shape) foram importados e processados no software Auto Cad Map 2013. A projeção geográfica determinada foi a UTM (Unidade Transversa de Mercator) - zona 22 sul, datum WGS-84.

Na sequência, as informações que interessavam foram vetorizadas, sob a criação de layers no software para cada tema. Por fim, elaborou-se três mapas temáticos que representam a evolução urbana, a localização dos empreendimentos e a distribuição espacial da renda média mensal e a localização dos empreendimentos nas zonas fiscais de 2012 (IPTU).

Com esses produtos cartográficos, tornou-se possível fazer a análise espacial dos novos produtos imobiliários. De acordo com alguns autores, “A ênfase da análise espacial é mensurar propriedades e relacionamentos, levando em conta a localização espacial do fenômeno em estudo de forma explícita. Ou seja, a ideia central é incorporar o espaço à análise que se deseja fazer" (CÂMARA et al., 2004, p.1). 


\section{ANÁLISE ESPACIAL DOS LOTEAMENTOS E CONDOMÍNIOS FECHADOS EM SANTA CRUZ DO SUL - RS}

O município de Santa Cruz do Sul está situado na área central da região do Vale do Rio Pardo - Rio Grande do Sul. Reconhecida pela sua importância mundial no mercado global do tabaco, esta cidade média apresenta atividades de produção industrial, beneficiamento e comercialização da produção do tabaco, além de se constituir em importante centro regional de comércio e serviços, notadamente aqueles ligados ao setor da saúde e educação.

A partir de 1970, desenvolveu-se em Santa Cruz do Sul a implantação de redes técnicas e modernos sistemas de engenharia, constituindo um meio técnico-científicoinformacional no território. A atividade agroindustrial do tabaco passa, portanto, a estabelecer importantes relações de beneficiamento industrial na região sul do Brasil, de produção de cigarros com algumas cidades brasileiras e com a economia internacional (SILVEIRA, 2003). Com isso, a população aumenta consideravelmente no munícipio, conforme dados da Tabela 1.

Tabela 1 - Santa Cruz do Sul-RS - Evolução da população urbana e rural 1940 - 2010

\begin{tabular}{ccrccc}
\hline \multicolumn{7}{c}{ População de Santa Cruz do Sul - RS, $1940-2010}$. \\
\hline Ano & Total & Urbana & $\%$ & Rural & $\%$ \\
$1940^{*}$ & 55.041 & 6.115 & 11,1 & 48.926 & 88,9 \\
$1950^{*}$ & 69.605 & 15.712 & 22,6 & 53.983 & 77,4 \\
$1960^{*}$ & 76.854 & 22.026 & 28,6 & 54.828 & 71,4 \\
1970 & 86.806 & 33.076 & 38,1 & 53.730 & 61,9 \\
1980 & 99.636 & 55.096 & 55,3 & 44.541 & 44,7 \\
$1991 \#$ & 117.773 & 78.955 & 67,00 & 38.818 & 33,0 \\
2000 & 107.632 & 93.786 & 87,10 & 13.846 & 12,8 \\
$2010^{1}$ & 118.374 & 105.190 & 88,62 & 13.184 & 11,13 \\
\hline
\end{tabular}

*Dados incluem a população de Vera Cruz, emancipado em 1959.

\#Dados incluem as populações dos distritos de Trombudo, Sinimbu e Gramado Xavier, emancipados em 1992.

Fonte: SILVEIRA, 2003. P. 89 e ${ }^{1}$ FEE, 2012. Org. Jonis Bozzetti

No transcorrer dos anos, a população total cresce consideravelmente, ultrapassando a faixa de 118 mil habitantes no último ano do levantamento. No entanto, verifica-se que a população rural diminui a cada década, sendo que em 1940 o percentual era em torno de $90 \%$ e, em 2010, apenas pouco mais de $10 \%$ residiam na zona rural. Logo, a população urbana experimenta um crescimento exorbitante nesse período, de modo que em 1940 residiam em torno de 6 mil habitantes e, em 2010, o número ultrapassa a faixa dos 100 mil. 
Comparando com o Estado do Rio Grande do Sul, que em 1970 já tinha a maior parte da população urbana, o município de Santa Cruz do Sul passou a concentrar a maioria dos habitantes residindo na cidade, anos mais tarde, por volta de 1980.

Nesses últimos 30 anos, a cidade vem experimentando um intenso e desigual processo de urbanização, refletindo na expansão da mancha urbana de forma significativa, conforme visualiza-se na Figura 2.

Figura 2 - Expansão da mancha urbana de Santa Cruz do Sul (1975 - 2012).

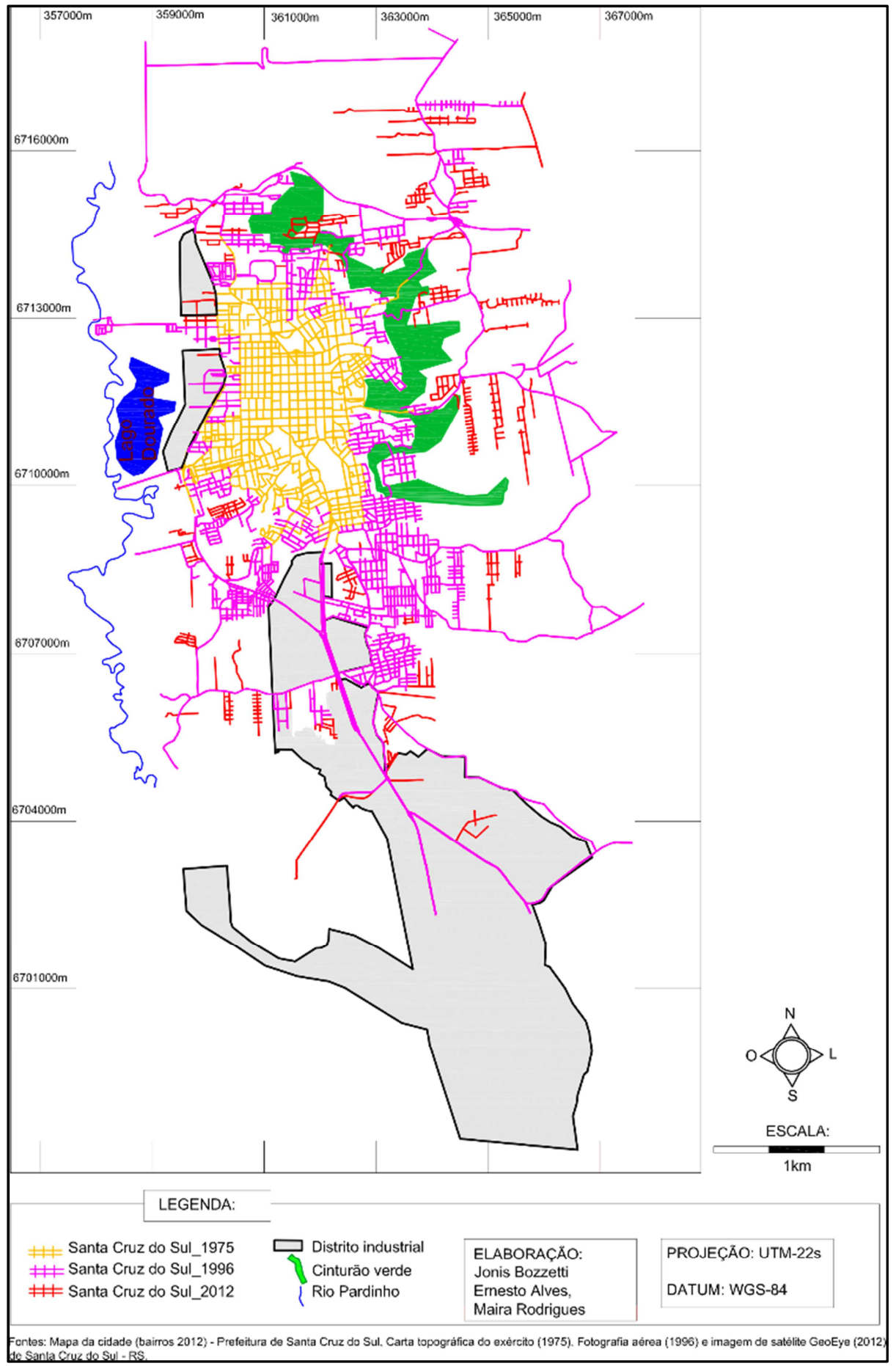


No período de 1975 a 1996, percebe-se a nítida expansão da mancha urbana para o sul, sobretudo, em direção aos bairros Arroio Grande, São João, Santo Antônio, Esmeralda, Castelo Branco, Faxinal Menino Jesus, Santa Vitória, Santuário e Pedreira. O aumento da demanda de mão de obra para trabalhar no setor agroindustrial do tabaco, atraiu migrantes de municípios e regiões vizinhas, que passaram a residir nessa área de expansão, muitas vezes, de maneira irregular na periferia da cidade (SILVEIRA, 2003).

Esse intenso crescimento teve como fator preponderante as supersafras de tabaco no final da década de 1980 e início dos anos 1990, com aumento de 127\% em 1998/1989 e de $228 \%$ nos anos 1992/1993, em relação às safras de 1977/1978. Tal fato contribuiu para a abertura de novos loteamentos e o aquecimento do setor imobiliário e da indústria de construção civil sob investidores locais, de municípios vizinhos e até mesmo funcionários das empresas de tabaco (SILVEIRA, 2003). Em pesquisa realizada, Silveira ressalta essa situação, enfatizando:

\begin{abstract}
Segundo nossa pesquisa junto ao cartório de registro de imóveis em relação a alguns loteamentos realizados nesse período, houve a participação desse segmento na aquisição de lotes de terra na área urbana e/ou em áreas externas ao perímetro urbano, como também, em alguns casos, na promoção de loteamentos através da constituição de empresas imobiliárias. Nesse sentido, poderíamos citar, entre outras, a atuação de Fernando Tatsch, de Walter Alberto Brand, de Harald Alberto Sohnle e de Philip Rudolph Van Harreveld, tradicionais empresários e/ou famílias do ramo fumageiro local (SILVEIRA, 2003, p. 103).
\end{abstract}

Outro fator de expansão da cidade nos últimos anos foi a criação da Universidade de Santa Cruz do Sul em 1993 e a demanda de novos espaços residenciais e de serviços para a comunidade acadêmica.

Ao norte e leste de Santa Cruz do Sul, principalmente no entorno do cinturão verde, encontramos atualmente a presença de loteamentos e condomínios fechados de alto-padrão cujo processo, em alguns casos, aconteceu pela transformação do solo rural em urbano. Dessa forma, nota-se que o aquecimento do mercado imobiliário e de investimentos no setor da construção civil, propulsionados pelo crescimento da produção de tabaco, foram fatores decisivos na produção de loteamentos e condomínios fechados nos últimos quinze anos. A presente conjuntura econômica que a cidade experimentou atraiu o olhar de investidores locais e regionais do setor imobiliário como mostra a Tabela 2. 
Tabela 2 - Produtos imobiliários e empresa responsável - Santa Cruz do Sul - RS

\begin{tabular}{|c|c|c|c|}
\hline Nome do empreendimento & $\begin{array}{l}\mathrm{N}^{\circ} \mathrm{de} \\
\text { Lotes }\end{array}$ & Total $\mathbf{m}^{2}$ & Empresa Responsável \\
\hline Lot. Costa Norte & 161 & $*$ & Campus Emp.Imobiliário \\
\hline Lot. Res. Das Figueiras & 305 & $257.424,33$ & Const.E Urb.Rech LTDA \\
\hline Cond. Jack-Land II & 8 & 10.371 .45 & Limit-Locações e Emp.LTDA \\
\hline Cond. Jack-Land & 15 & 50.000 .00 & André Xavier e Outros \\
\hline Lot. Cond. Fech. Ingo Inácio Reis & 9 & 3.777 .55 & Ingo Inácio Reis \\
\hline Lot. Cond. Fech. Bela Vista & 22 & $9.831,45$ & Gerson Sampaio e Outros \\
\hline Lot. Cond. Fech. Terras Altas & 56 & $416.665,23$ & Lauro Garmatz e VJS-Emp.Neg.Imob.Ltda. \\
\hline Cond. Fech. & 14 & $15.000,000$ & Suprema Neg.Imb.Ltda. \\
\hline Lot. Costa Leste & 15 & $17.088,86$ & João Dick Imóveis Ltada. \\
\hline Lot. Costa Leste $2^{\mathrm{a}}$ etapa & 21 & $22.420,84$ & João Dick Imóveis Ltada. \\
\hline Lot. Cond. Fech. & 20 & $3.513,20$ & João Dick Imóveis Ltada. \\
\hline Lot. Fech. Country Boulervard & 69 & $98.267,97$ & Const.E Urb.Rech Ltada. \\
\hline Cond. Fech. & 38 & $42.401,84$ & Blk Empr. Imob. Ltada. \\
\hline $\begin{array}{l}\text { Cond. Fech. Golf Villas } \\
\text { Lot. Cond. Urb. Reser. dos }\end{array}$ & $*$ & $120.600,00$ & Martim EIDT e outros \\
\hline Passaros & 325 & $375.284,57$ & João Dick Imóveis Ltada. \\
\hline Cond. Resid. Coutry Ville & 188 & $237.155,39$ & Construfácil-Agrop.Com.E Serv.Ltda Fik \\
\hline Lot. Golf Residence & 90 & $84.064,39$ & Construfáacil-Agrop.Com.E Serv.Ltda. \\
\hline Cond. Fech. Casa da Pedra & 20 & $*$ & $\begin{array}{l}\text { Blk Empr. Imob. Ltda. } \\
\text { Kartoll Empreendimentos Imobiliários }\end{array}$ \\
\hline Projeto de Lot. Cond. Belle Ville & 370 & $190.244,45$ & Ltada. \\
\hline Projeto de Cond. Serra Azul & 357 & $182.232,64$ & Serra Azul Imóveis Ltda. \\
\hline
\end{tabular}

*Dados não fornecidos.

Fonte: Prefeitura Municipal de Santa Cruz do Sul, 2013.

No entanto, essa dinâmica vem revelando o aprofundamento do processo de segregação sócio espacial, marcado pela desigual ocupação do solo urbano. Com a presença de novos empreendimentos, acarreta-se na cidade significativas transformações, produzidas por agentes imobiliários que atuam diretamente na promoção dessa nova forma de moradia.

Diferentes empresas participam deste processo empreendimentos, seja na incorporação, construção ou comercialização. Vários destes produtos imobiliários possuem área total e número de lotes significativos, representando grande consumo de espaço da cidade santa-cruzense.

Nesse sentido, a lógica especulativa do mercado imobiliário se processa na localização dos loteamentos e condomínios fechados ao entorno no Cinturão Verde. Tal estratégia busca proporcionar maior qualidade de vida aos moradores, dotada de excelente infraestrutura, além de oferecer um ambiente de convívio com a natureza dada a existência das áreas verdes.

O alto-padrão dos empreendimentos muitas vezes acompanhado por salões de festas e campos de futebol/tênis, por exemplo é direcionado à demanda solvável da população, que 
procura lugares seguros e confortáveis para residir. Com isso, o valor do solo urbano aumenta exorbitantemente nesses locais, ocasionando na renda diferencial da terra. Essa valorização condiciona a reprodução do capital imobiliário, tendo presente que a comercialização desses empreendimentos traduz-se em altas margens de lucros aos agentes imobiliários.

Nessa lógica de mercado é importante frisar o papel do poder público municipal nesse processo. Chama atenção que para garantir a preservação das áreas verdes, a população de baixa renda foi direcionada para os loteamentos populares da cidade, onde a infraestrutura se fez acompanhada pela demora de atendimento e em função da mobilização dos moradores. Logo, a mesma fiscalização e controle antes dispensados com a população de baixa renda não vêm sendo aplicados da mesma forma na produção dos loteamentos e condomínios fechados, visto, inclusive, o recente desmatamento de áreas do cinturão para as suas construções (SILVEIRA, 2003).

Além disso, estas práticas espaciais acabam acentuando a segregação urbana em Santa Cruz do Sul, dadas as diferenças de renda entre bairros do sul com os bairros do norte/leste da cidade, conforme percebe-se na Figura 3.

Assim, a população com renda média mensal per capita mais baixa, considerando pessoas de 10 anos ou mais de idade, concentra-se, sobretudo, em áreas no sudoeste da cidade, próximas ao distrito industrial. Já os bairros com população com renda maior, como o Country, Jardim Europa e Verena, situam-se nas margens do Cinturão Verde.

Essa configuração espacial da cidade santa-cruzense faz parte de ações de políticas públicas, as quais legitimam os interesses e condições de reprodução do capital imobiliário de atores hegemônicos, o que por sinal, acaba promovendo cada vez mais a segregação espacial (SILVEIRA, 2003).

Ainda nesse sentido, a forma como é tributada o Imposto Predial e Territorial Urbano (IPTU), apresentada na figura 4 no que diz respeito ao valor do metro quadrado por lote, revela o tratamento desigual com os contribuintes santa-cruzenses.

O zoneamento fiscal em Santa Cruz do Sul, adotado no ano de 2012, estava representado da seguinte forma: a área central, identificada como Zona 1, possui o maior valo com $\mathrm{R} \$ 503,72$ por metro quadrado. Logo, quanto mais para a periferia, menor é o valor, atingindo $\mathrm{R} \$ 31,47$ por metro quadrado na zona 8 . Tal zoneamento está defasado pois teve como base o levantamento de campo realizado em 1996, quando se caracterizou as distintas zonas da cidade de acordo com o tipo de ocupação e de usos predominantes do solo urbano, bem como a distribuição da infraestrutura, equipamentos e serviços urbanos então disponíveis na cidade. 
Figura 3- Mapa de renda média mensal em Santa Cruz do Sul - 2010.

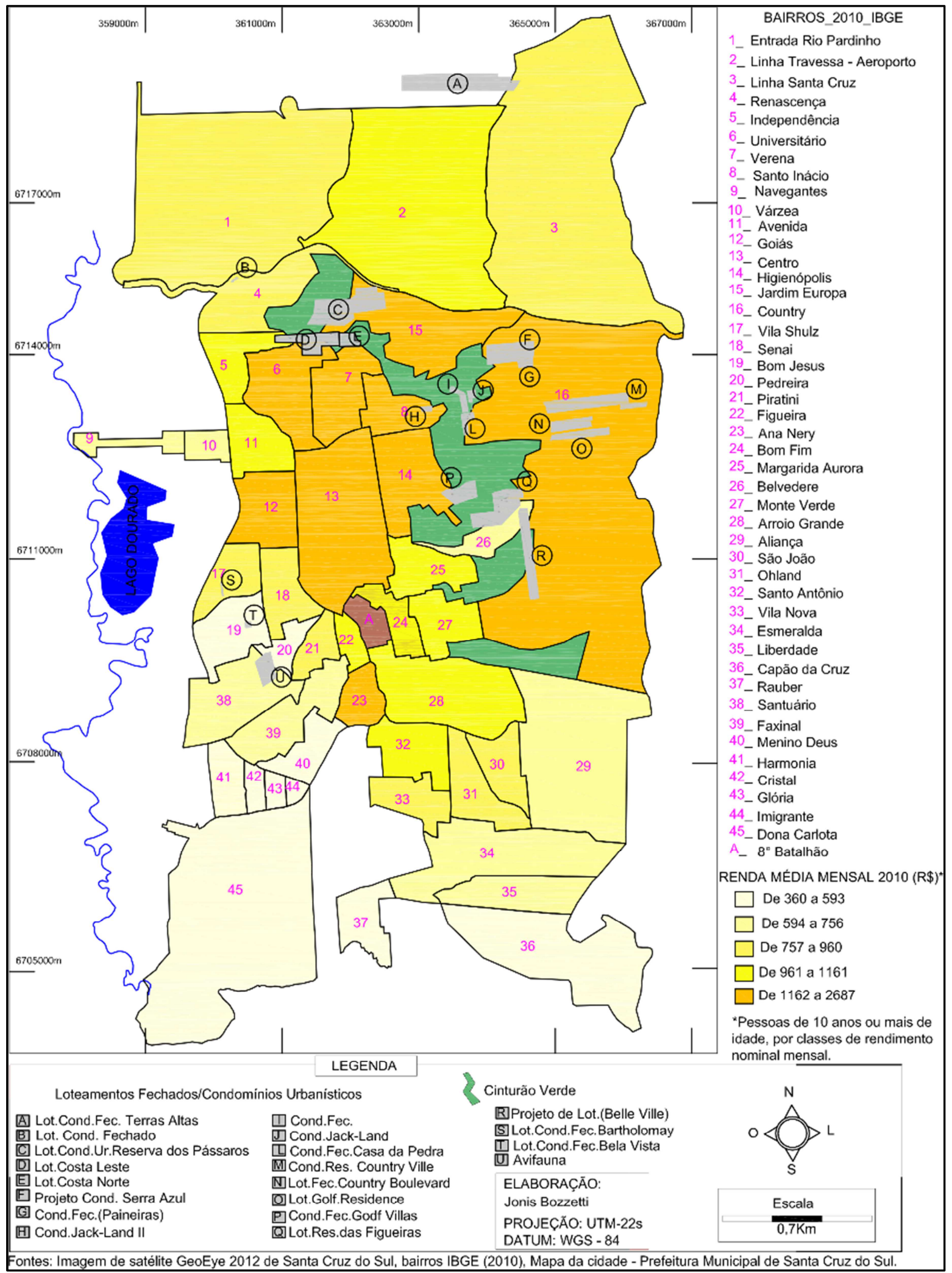

Desta forma, percebe-se a presença de loteamentos e condomínios fechados, tais como o Country Ville e o Golf Residence, na zona fiscal de menor valor. Essa mesma faixa de valor que define o total do tributo IPTU vem servindo de referência para a cobrança deste 
imposto para as pessoas de baixa renda que residem nos bairros periféricos mais pobres da cidade, como o Bom Jesus e o Santa Vitória.

A falta de atualização no zoneamento fiscal implica em evidente injustiça tributária na arrecadação municipal, pois essa lógica não acompanha as transformações e (re)produções do espaço urbano de Santa Cruz do Sul. Situações semelhantes como essa estão presentes em várias cidades brasileiras, o que reflete na falta de mapeamento e estudos técnicos que corrijam essas distorções na cobrança do IPTU dos municípios.

\section{Figura 4 - Mapa de zoneamento fiscal em Santa Cruz do Sul - 2012.}

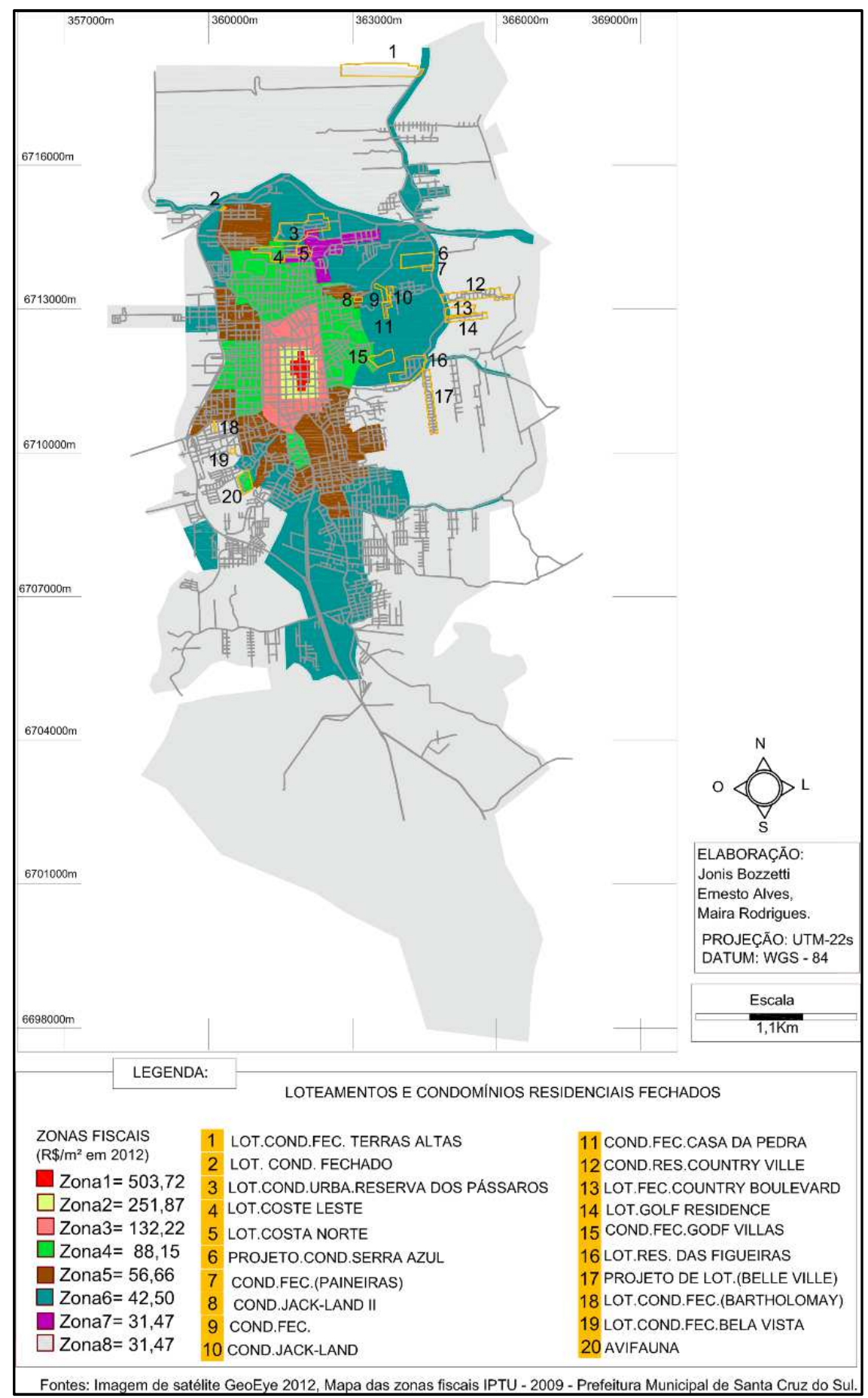


Como visto, esse intenso e desigual processo de urbanização na cidade nos últimos 30 anos, promovido por diferentes agentes sociais, vem acentuando a segregação urbana com a produção dos loteamentos e condomínios fechados. As ações do poder público municipal, vinculada aos interesses dos atores hegemônicos que participam das transformações do espaço urbano local, vêm favorecendo a acumulação e reprodução do capital, em um mercado imobiliário excludente, especulativo e seletivo.

\section{CONSIDERAÇÕES FINAIS}

Os estudos de novos produtos imobiliários em cidades médias vêm revelando importantes reflexões no processo recente de reestruturação urbana. $\mathrm{O}$ crescimento econômico vem beneficiando segmentos da sociedade que detêm o poder de reproduzir o capital, gerando exclusão social e ferindo o direito à cidade de todos os demais moradores.

Este primeiro olhar sobre a produção desses empreendimentos em Santa Cruz do Sul, com o auxílio de técnicas de geoprocessamento, foi possível obter resultados empíricos que auxiliaram para compreender a evolução urbana, segregação espacial e injustiça fiscal na produção de loteamentos e condomínios fechados na cidade.

Resultado do aumento da economia local, sobretudo pela crescente produção de tabaco nos últimos anos, tais empreendimentos revelam novas dinâmicas urbanas aliadas às práticas espaciais de agentes imobiliários. Nesse processo, o poder público municipal também vem promovendo ações que favorecem os agentes que atuam na produção dessa nova forma de moradia.

\section{REFERÊNCIAS}

BRANCO, M. L. C. Cidades Médias no Brasil. In: SPOSITO, E. S.; SPOSITO, M. E. B.; SOBARZO, O. (org.). Cidades médias: produção do espaço urbano e regional. São Paulo: Expressão Popular, 2006.

CÂMARA, G.; DAVIS, C.; MONTEIRO A.M.V. Introdução à ciência da geoinformação. INPE, 2001, Disponível em: <http://mtcm12.sid.inpe.br/col/sid.inpe.br/sergio/2004/04.22.07.43/doc/publicacao.pdf $>$. Acesso em: 09 de dez. de 2013.

CÂMARA, G. et al. Análise Espacial e Geoprocessamento. In: CÂMARA et al. (org.) Análise Espacial de Dados Geográficos. Brasília, 2004. Disponível em: 〈http://www.dpi.inpe.br/gilberto/livro/analise/cap1-intro.pdf $>$. Acesso em: 01 de jan. de 2014. 
CARLOS, A. F. A cidade. São Paulo: Contexto, 1992.

CORRÊA, R. L. O espaço urbano. 2 ed. São Paulo: Ática, 1989.

MAIA, D. S. Cidades Médias e pequenas do nordeste: conferência de abertura. In: LOPES, D.M.F.; HENRIQUE, W. (ORG.). Cidades médias e pequenas: teorias, conceitos e estudos de caso. -Salvador: SEI, 2010.

SILVEIRA, R. L. L. da. Cidade, corporação e periferia urbana: acumulação de capital e segregação espacial na (re)produção do espaço urbano. Santa Cruz do Sul: EDUNISC, 2003.

SPOSITO, M. E. B. Loteamentos fechados em cidades médias paulistas - Brasil. In: SPOSITO, E. S.; SPOSITO, M. E. B.; SOBARZO. O. (org.). Cidades médias: produção do espaço urbano e regional. São Paulo: Expressão Popular, 2006. 